See Article page 63.

\section{Commentary: Evoke the unlikely, not too late}

\author{
Amedeo Anselmi, MD, $\mathrm{PhD},{ }^{\mathrm{a}}$ and \\ Mathieu Revest, $\mathrm{MD}, \mathrm{PhD}^{\mathrm{b}}$
}

When speaking of Aspergillus spp (with Aspergillus fumigatus and Aspergillus flavus being responsible of approximately $90 \%$ of all clinically evident human contaminations), cardiothoracic surgeons usually think of invasive, prognostically ominous infections most frequently seen in immunocompromised patients. The case reported by Leow and colleagues ${ }^{1}$ in this issue of the Journal embodies the menace embodied by such a rare entity and its capacity to occur in even immunocompetent hosts. Airborne contamination from these ubiquitous fungal spores represents the elective mode for development of the infection; this case also demonstrates the predilection of Aspergillus to the aortic tissue, the damage induced by surgery (eg, aortotomy, proximal bypass graft anastomosis, cannulation), and its exposure to contaminated air, likely representing the conditions for homing. These features are concordant with the previously largest published series, ${ }^{2}$ in which Aspergillus aortitis occurred in patients who were immunocompetent preoperatively and had not received previous corticosteroid treatment and evolved without involvement of native or prosthetic heart valves. Conversely, systemic fungal dissemination and mycotic emboli are more likely. Based on the present case, hemoptysis due to pseudoaneurysm erosion into the lung can be added to the list of the possible clinical manifestations.

From the a Division of Thoracic and Cardiovascular Surgery, Pontchaillou University Hospital, Rennes, France and ${ }^{\mathrm{b}}$ Infectious Diseases and Intensive Care Unit, CHU Rennes, Rennes, France.

Disclosures: The authors reported no conflicts of interest.

The Journal policy requires editors and reviewers to disclose conflicts of interest and to decline handling or reviewing manuscripts for which they may have a conflict of interest. The editors and reviewers of this article have no conflicts of interest.

Received for publication Jan 9, 2021; revisions received Jan 9, 2021; accepted for publication Jan 13, 2021; available ahead of print Jan 19, 2021.

Address for reprints: Amedeo Anselmi, MD, PhD, Division of Thoracic and Cardiovascular Surgery, Pontchaillou University Hospital, Rennes, France (E-mail: amedeo.anselmi@chu-rennes.fr).

JTCVS Techniques 2021;6:66-7

2666-2507

Copyright (c) 2021 The Authors. Published by Elsevier Inc. on behalf of The American Association for Thoracic Surgery. This is an open access article under the CC BY-NCND license (http://creativecommons.org/licenses/by-nc-nd/4.0/).

https://doi.org/10.1016/j.xjtc.2021.01.012
Check for updates

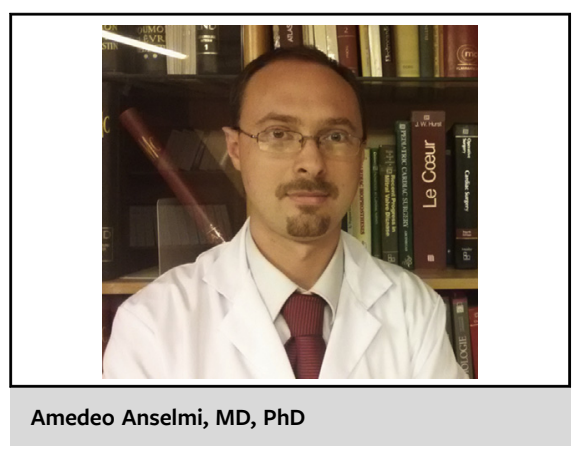

CENTRAL MESSAGE

The clinician's work can be frus-

trating with such entities as

Aspergillus aortitis following

cardiac surgery. These are not

always thought of, yet timeliness

of diagnosis can (hopefully) be

life-saving.

Based on the above elements, one regretfully cannot suggest shared baseline patient characteristics leading to increased postoperative likelihood of this rare aortitis, perhaps except a previous history of pulmonary aspergilloma or known airway colonization by Aspergillus spp fungi. Therefore, it is difficult to propose specific pharmacologic prophylaxis. Then our main preventive weapon might be to adopt the optimal environmental strategies with respect to the ventilation system and high-efficiency particulate air filtering in the operating rooms. It is also of paramount importance to avoid performing cardiac operations in the event of concomitant construction work adjacent to the surgical wards.

The present case also underlines the anatomic aggressiveness of Aspergillus-related aortic pseudoaneurysm, as it evolved to fatal rupture in less than 2 months after the index surgery. This accelerated progression is a feature truly uncommon in "mechanical" or even nonfungal infectious anastomotic pseudoaneurysms that we are accustomed to seeing and treating in aortic surgery and again supports the major importance of early diagnosis, which can truly have life-saving value. Here chest computed tomography scan was the pivotal examination allowing institution of the appropriate management algorithm; echocardiography also can be useful in raising the suspicion of ascending aortic lesion. 
Aspergillus aortitis should be kept in mind as a possible cause of early ascending aortic pseudoaneurysm or of unexplained fever after cardiac surgery, similar to another rare but prognostically unfavorable cause: Mycobacterium chimaera endocarditis. ${ }^{3}$ Both have a iatrogenic origin, are typically seen in cardiac surgery patients, and require early diagnosis for successful treatment. Both necessitate dedicated mitigation strategies and might be the object of professional liability disputes should these strategies be inadequate. In conclusion, although Aspergillus aortitis is not unknown to our literature, the current illustrative case is very useful as a memory aid, given the difficulty in suspecting and detecting this disease in a timely fashion.

\section{References}

1. Leow L, Qian Q, Chew KL, Sorokin V. Unusual presentation of Aspergillus aortitis after aortic valve surgery with massive haemoptysis. J Thorac Cardiovasc Surg Tech. 2021;6:63-5.

2. Sanchez-Recalde A, Maté I, Merino J, Simon R, Sobrino J. Aspergillus aortitis af ter cardiac surgery. J Am Coll Cardiol. 2003;41:152-6.

3. Vendramin I, Peghin M, Tascini C, Bortolotti U, Livi U. Mycobacterium chimaera infection after cardiac surgery: catastrophic effects of delayed diagnosis. J Card Surg. 2021;36:408. 